Revista

Multi-Ensayos

Vol. 5, $\mathrm{N}^{\circ} 10$

ISSN: 2412-3285

https://multiensayos.unan.edu.ni

DOI: https://doi.org/10.5377/multiensayos.v5i10.8881

\title{
Dimensión ambiental del desarrollo social
}

\section{Environmental dimension of social development}

José Luis Almendárez Castillo'

Recibido: 01 de junio de 2019. Aceptado: 26 de junio de 2019

\section{RESUMEN}

En la construcción de una perspectiva de dimensión ambiental para el desarrollo social es de suma importancia la participación de todos los sectores e instituciones sociales, particularmente de las instituciones de educación superior. La exigencia de respuestas a la problemática ambiental aparece desde los años setenta con el nacimiento de la educación ambiental. Desde las primeras reuniones internacionales en esta materia, se estableció la urgente necesidad de incorporar la perspectiva ambiental en la educación superior, a fin de generar los cambios internos requeridos, y así crear una capacidad que les posibilite ofrecer respuestas pertinentes a los problemas ambientales y sean partícipes activas en la construcción de escenarios deseables de desarrollo.

Palabras claves: dimensión ambiental; desarrollo social; problemática ambiental; educación superior; escenarios deseables.

\section{ABSTRACT}

In the construction of a perspective of environmental dimension for the social development there is of supreme importance the participation of all the sectors and social institutions, particularly of the higher education institutions. The answers demand to the environmental problems appears from the seventies with the birth of the environmental education. From the first international meetings in this matter, there was established the urgent need to incorporate the environmental perspective in the higher education, in order to generate the required internal changes, and this way to create a capacity that makes possible to them to offer pertinent answers to the environmental problems and they are active participants in the construction of desirable stages of development.

Keywords: environmental dimension; social development; environmental problems; higher education; desirable stages.

1 Docente UNAN-Managua/FAREM-Estelí. Correo electrónico: joseluisalmendarez@yahoo.com. (c) 2019 Revista Multi-Ensayos. 


\section{INTRODUCCIÓN}

El propósito del presente ensayo es promover en la conciencia humana la importancia de garantizar un perfecto equilibrio entre la sociedad y la dimensión ambiental para fortalecer el conjunto de valores, actitudes y motivaciones que rigen las relaciones entre la sociedad y la naturaleza y las formas como dichas relaciones se traducen en los sistemas de producción y apropiación de los recursos productivos, así como en el manejo individual y colectivo de los recursos naturales, el equilibrio ecológico y la preservación y calidad de la vida.

El evidente deterioro ambiental al cual se enfrenta nuestra civilización, constituye una seria amenaza para la supervivencia de la especie humana por cuanto afecta sustancialmente la disponibilidad de recursos para mantener el ritmo de producción de bienes y el avance tecnológico, característicos de la sociedad actual. (Arias, 1995:3)

El autor señala con mucha preocupación que la calidad de vida está en riesgo producto de la interacción inadecuada de los seres humanos con la dimensión ambiental principal recurso para el desarrollo social, pretendemos realizar grandes obras de desarrollo sin romper el equilibrio sociedad versus dimensión ambiental el que juega, nos preocupamos por la salud económica, salud física, etc, sin tomar en cuenta que todo está ligado a la primera, es decir a la salud ambiental de donde se desprende el accionar de los seres humanos, de ahí se deriva la calidad de vida de las sociedades sin interesar su status económico, político y social. Por tal razón debemos de cuidar esta salud que es la menos apreciada pero es nuestro gran capital de vida.

\section{DESARROLLO}

La educación por supuesto en todos los niveles incluyendo la universitaria es posible que contribuya a detener el deterioro de la dimensión ambiental y lograr el desarrollo social aspecto tan esencial que toda sociedad pretende alcanzar pero que cada día se torna más y más difícil.

De acuerdo con lo expuesto se antoja prioritario incluir la DIMENSION AMBIENTAL en los programas educativos a todo nivel. (Arias, 1995:3)

El bienestar está ligado a numerosos factores vitales, como el aire puro para respirar; el agua y los alimentos sin contaminantes; los asentamientos aptos, a escala humana, sin ruidos ni vibraciones, sin la congestión, la promiscuidad y la pérdida diaria de tiempo para llegar al trabajos a la vivienda o a la escuela; el hábitat higiénico, funcional y acogedor; y, también, el ambiente tranquilo necesario para que la depredación psicosocial no afecte tan seriamente la salud emocional de la población de los grandes centros urbanos (Gligo, 2006: 69)

La dimensión ambiental vista desde el enfoque de este autor es excelente, pero si analizamos la situación actual es terriblemente ajena a este gran aporte, aire puro muy poco se puede respirar porque las 
ciudades están inundadas de grandes industrias que venden la idea de desarrollo social a través de la transformación de sus productos, inclusive grandes naciones del mundo se han negado a firmar protocolos que garantizan la estabilidad ambiental de nuestro planeta, el tránsito vehicular es otro elemento que ha deteriorado profundamente la calidad del aire que respiramos tan es así que existen países que programan la circulación de vehículos de acuerdo a programaciones especiales.

El agua y los alimentos deben ser puros sin contaminantes, pero nos preguntamos actualmente, ¿Se cumple este requisito tan fundamental para la vida humana?, tendríamos tantas respuestas y no solamente una, los consumidores diríamos no, los grandes inversionistas dueños del capital dirían sí, pero cada vez el agua y los alimentos están más contaminados producto de la manipulación para mejorar la producción inclusive desde el punto de vista genético, lo cual provoca que la esperanza de vida de la población disminuya cada día.

Los recursos naturales constituyen el principal capital y que funciona también como recurso estratégico para los países del tercer mundo en la actual economía mundial dominada por una tecnología cada vez más sofisticada y una mayor concentración del capital.

Ello será así, y en creciente escala, en la medida en que los países industrializados agoten los suyos por excesivo consumo de tecnologías depredadoras y desperdiciadoras de recursos y de acumulación acelerada de contaminación.

La provisión de alimentos y de materias primas será en el futuro un factor crítico en dichos países si continúan las actuales tendencias de consumo y depredación.

Es por tanto fundamental hacer que la sociedad en todos los niveles se concientice sobre la importancia de la vegetación, el agua y otros recursos particularmente los bosques y selvas húmedas tropicales y las cuencas hídricas tienen en la configuración del clima y de la provisión de oxígeno para nuestro planeta, el cual es nuestro dador de vida a través de la dimensión ambiental para lograr el desarrollo social.

La dimensión ambiental para el desarrollo social es muy clara pero por qué no actuamos positivamente sobre el caso, veamos lo siguiente, los países del tercer mundo y particularmente los latinoamericanos, no parecen haberse percatado del valor potencial y estratégico de sus recursos naturales y continúan subestimándolos y explotándolos irracionalmente al ritmo depredador impuesto por los países industrializados, como se mencionaba en párrafos anteriores, es necesario educar a la sociedad, es nuestra única salvación.

Al mismo tiempo continúan acelerando el proceso de deterioro de sus mejores tierras agrícolas, sus cuencas hidrográficas y la cobertura vegetal de sus laderas, valles y llanos.

En esta forma están dilapidando recursos productivos de beneficio inmediato y también los recursos estratégicos que podrían otorgarles una ventaja comparativa en la economía mundial del futuro, destruimos lo nuestro para la sobrevivencia de otros. 
El medio ambiente naturaleza: Esta concepción remite a la necesaria actitud de apreciación, respeto y conservación del medio físico natural. Aquí el concepto de ambiente alude al entorno original, puro, del cual la especie humana se ha distanciado, lo que queda de manifiesto por las actividades antrópicas que han provocado su deterioro. (García, Priotto, 2009:31)

La sociedad se ha distanciado de su principal fuente de vida "la dimensión ambiental" esto es muy válido pero además de los sistemas educativos qué pasa con las leyes que protegen nuestro ambiente, quien las aplica, cuáles son las sanciones impuestas, ya sabemos inclusive que en Nicaragua existe una institución para velar por la dimensión ambiental pero en realidad no se observan resultados, ni pasados, presentes o acciones futuras a tomar.

Nos espera entonces el final de la vida en el planeta tierra, porque aún con los grandes recursos tecnológicos no se han encontrado planetas similares al nuestro para trasladarnos y colonizarlos, pero aún hay tiempo no para que nos salven sino para salvarnos de la debacle de la extinción.

Analizando otro caso importante, los bosques húmedos cumplen una función vital a nivel nacional y planetario en la generación de oxígeno, la remoción de material gaseoso y en suspensión, el mantenimiento del balance de carbono, de la calidad global del aire, del régimen planetario de lluvias y, en general, de la estabilidad atmosférica, pero ¿lo sabe la población a conciencia?¿ Lo saben los niños? ¿Lo sabe la sociedad? estas interrogantes no se responden, porque las acciones mismas tomadas en los bosques segovianos, en los bosques del caribe, etc, dan respuesta total a estas preguntas de vida.

Es fundamental que el crecimiento económico deba ir acompañado de la preservación ambiental, finalmente, debería plantearse la preocupación sobre la necesidad de dilucidar si en esta relación ambiente-economía la contaminación constituye un factor inevitable; o, si al contrario, se trata de un fenómeno controlable y en qué medida.

Por una parte es indiscutible que todo proceso de transformación física, química o biológica lleva aparejados pérdidas relativas de recursos y descargas de energía, subproductos, residuos y desechos, así como modificaciones en la dinámica del respectivo ecosistema, pero la inteligencia humana ha creado obras indescriptibles, por qué no hacer al similar para el tratamiento de basuras tóxicas que acarrean problemas de salud en lugar de desarrollo a la sociedad.

Pero, por otra parte, también es cierto que la naturaleza cuenta con una gran capacidad de autogeneración suficientemente adecuada para asegurar el necesario equilibrio dinámico entre las demandas del sistema económico y la oferta de recursos del sistema natural.

Podría decirse a primera vista que en la dialéctica de las relaciones conflictivas entre el ambiente y la economía, el hombre y la sociedad tienen mayor capacidad de iniciativa y de movimiento y su ingenio los provee aparentemente de mayores "recursos" estratégicos y tácticos para agredir y "dominar" a la naturaleza. 
La dimensión ambiental "dispone" de una capacidad de reacción ante el comportamiento irracional de la sociedad, tornándose menos pródiga y productiva en materia de recursos, y menos acogedora en términos de hábitat.

Las expresiones más visibles de las tensiones entre la sociedad y su entorno se pueden apreciar en el deterioro de estos entornos, el deterioro de la calidad de vida, y el bienestar social. Entre las expresiones del deterioro de los entornos, podemos mencionar las siguientes: el agotamiento y contaminación de los recursos, la inestabilidad climática, la pérdida del patrimonio cultural, el incremento del nivel de los riesgos, etc. (Calderón, Norid, 2014:31)

Entre las expresiones más sentidas del deterioro de la calidad de vida y el bienestar social, podemos mencionar las siguientes: el aumento de los conflictos sociales, el aumento de la dimensión de los desastres, la disminución de las capacidades de satisfacción de las futuras generaciones, etc. (Calderón, Norid, 2014:31)

Así, en la medida en que el indiscriminado progreso tecnológico para la producción y la ampliación de la demanda global de bienes y servicios aumenta, surge una dinámica conflictiva según la cual en la medida en que la presión y la agresividad de la sociedad es mayor, la naturaleza es menos pródiga y hasta llega a ser también "agresiva", porque sus ciclos vitales internos y sus recursos están siendo depredados, como observa en la apreciación de los autores, el ser humano destruye la dimensión ambiental para construir desarrollo, pero en realidad lo que se crean son conflictos, producto de las insatisfacciones de las demandas que cada día crecen a lo interno de la sociedad.

\section{CONCLUSIÓN}

No se puede escapar al análisis, la consideración de que los sistemas económicos y sus respectivos estilos de desarrollo son creados y puestos en vigencia por la sociedad en ciertas coyunturas históricas concretas; y que, además, no existe un sistema económico, ni una estrategia económica, ni una política económica, ni un "estilo de desarrollo" únicos, inevitables, e irreversibles, por tal razón la dimensión ambiental debe ser el primer factor económico a tratar en una mesa de políticas económicas y sobre todo en los países cuyo único capital son los recursos que nos ofrece la dimensión ambiental para el desarrollo social.

Es muy importante en relación con los países latinoamericanos, los cuales pueden extraer de este tipo de análisis conclusiones prácticas. Una de ellas es que no existen razones históricas y políticas suficientemente válidas para que estos países se comprometan con determinados sistemas y "estilos" de desarrollo intrínsecamente degradantes. Otra es que las tendencias de desarrollo vigentes en estos países no son forzosamente irreversibles. Otra es que la experiencia negativa de las mayorías de los países centrales en materia ambiental no tiene por qué ser forzosamente reproducida en los países periféricos y, antes bien, ella debería ser aprovechada como una lección que no debe repetirse. 
En tales condiciones podría concluirse que las relaciones ambiente-economía son susceptibles parcial y totalmente de control y maniobra por parte de las fuerzas sociales en el mundo, es de vida o muerte las decisiones que se tomen a partir de este momento en cuanto a la dimensión ambiental para el desarrollo social, convencer que no todo desarrollo es progreso social, en Nicaragua el gobierno se preocupa por tal situación tan es así que a los niños y niñas en educación primaria, a los y las jóvenes en educación media y superior, se les forma en tal sentido pero el contexto familiar y social distorsionan el trabajo realizado en educación y queda en teoría lo que realmente debería ser acción en un 100\%, porque de eso depende el futuro de la humanidad.

\section{REFERENCIAS}

Carrasco, M. T. (1996). La dimensión ambiental: un reto para la educación de la nueva sociedad. Santa Fé, Colombia.

Gligo, N. (2006). Estilos de desarrollo y medio ambiente en América Latina, un cuarto de siglo después. Santiago: Talleres Naciones Unidas.

Martínez, R. Q. (2007). Indicadores ambientales y de desarrollo sostenible: avances y perspectivas para América Latina y el CAribe. Santiago, Chile: Naciones Unidas Chile.

Mora, L. V. (2013). Dimensió ambiental, desarrollo sostenible, y sostenibilidad ambiental del desarrollo. Colombia.

Plan de desarrollo Chiapas. (2012). Gestión ambiental y desarrollo. Chiapas, México.

René Calderón, R. N. (2014). Educación Ambiental. Lima: Gráfica Kike. 